\title{
PEMBERDAYAAN POS PAUD DAN WAHANA DOLANAN MENDIDIK KARAKTER BAGI ANAK USIA DINI DI KABUPATEN MADIUN
}

\author{
Fida Chasanatun ${ }^{1)}$, Ervan Johan Wicaksana ${ }^{2)}$, Sofia Nur Afifah ${ }^{3)}$ \\ ${ }^{1)}$ FIP, IKIP PGRI MADIUN \\ email: penulis_1@abc.ac.id \\ ${ }^{2)}$ FIP, IKIP PGRI MADIUN \\ email: ervan_jw@yahoo.com \\ ${ }^{3)}$ FIP, IKIP PGRI MADIUN \\ email: soffi.afifah@yahoo.com
}

\begin{abstract}
By years, children need a more complete educational stimulation, thus requiring additional educational services are conducted by environmental agencies and early childhood education at preschool. Stimulation education conducted in home (home base) and is done outside of home (center base) should be aligned and mutually supportive, in order to obtain maximal benefit. Outside education stimulation begins after baby 3 months or 6 months of aged. Unfortunately the service children of this age have a limited presence. If anything, not necessarily affordable to the community, both in terms of distance and cost. Post existence of early childhood as a form of early childhood kind Unit (SPS) is intended to bridge those needs. In the implementation of Post early childhood education can be integrated with a variety of early childhood services programs that already exist in the community such as: IHC, BKB (BKB), Parks Childcare (TPA), Play Group (PG). SPS program is intended for people who are not ready to engage her in a more intensive early childhood services, whether by reason of inconvenience escort, cost and other factors. Post early childhood education program will be implemented in some areas of Madiun regency that have not been getting early childhood education intensive and help parents to better know how to give good education to children at an early age period. The above options based on the need for early childhood education and have not been reached by the presence of intensive early childhood education in these areas. This program will also help parents to better know how to give good education to children at an early age period.
\end{abstract}

Keywords: Post early childhood education, rides Dolanan Educate Character, Childhood.

\section{PENDAHULUAN}

Dalam pelaksanaannya Pos PAUD dapat diintegrasikan dengan berbagai program layanan anak usia dini yang telah ada di masyarakat seperti : Posyandu, Bina Keluarga Balita (BKB), Taman Penitipan Anak, Pelayanan, Bina Iman Anak atau layanan terkait lainnya. Program SPS diperuntukkan bagi masyarakat yang belum siap mengikutsertakan anaknya dalam layanan PAUD yang lebih intensif, baik karena alasan kerepotan mengantar, biaya maupun faktor lainnya.

Perguruan tinggi merupakan bagian yang tak terpisahkan dengan sistem pendidikan nasional, memiliki peran sebagai dinamisator pembangunan masyarakat melalui pengembangan masyarakat, yang tugasnya antara lain adalah mengembangkan sumber daya manusia (SDM) yang berbasis pada penguasaan ilmu pengetahuan dan teknologi dan seni (IPTEKS) secara representatif, yang berlandaskan iman dan taqwa (IMTAQ), agar memiliki dampak positif dalam kehidupan masyarakat.

Pada pelaksanaan pengabdian perguruan tinggi tersebut sebagiannya dilaksanankan melalui kegiatan Iptek Bagi Masyarakat $\left(\mathrm{I}_{b} \mathrm{M}\right)$, yang akan dilaksanakan oleh kami selaku dosen IKIP PGRI MADIUN bersama mahasiswa. Pemusatan kegiatan pemberdayaan Pos PAUD tersebut difokuskan anak-anak yang belum mendapatkan pendidikan Anak Usia Dini karena belum terjangkau oleh PAUD intensif serta membantu orang tua agar lebih mengetahui cara memberikan pendidikan yang benar bagi anak pada masa usia dini yang tersebar di di 
Kabupaten Madiun. Masih banyak anak-anak yang belum mendapatkan pendidikan anak usia dini, sedangkan pendidikan untuk anak usia dini sangatlah penting karena banyak yang menyebutkan masa usia dini adalah masa keemasan bagi anak, karena pada masa itu anak mulai berfikir dan mulai mengenal segala sesuatu yang ada disekitarnya. masa usia dini adalah masa yang sangat penting karena tidak akan terlulang lagi pada masa berikutnya. Jadi dapat disimpulkan dari latar belakang itu kami berencana mendirikan POS PAUD dan Wahana Dolanan Mendidik Karakter Bagi Anak Usia Dini di Kabupaten Madiun untuk membantu anak-anak di Kabupaten Madiun yang belum mendapatkan pendidikan dan membantu orang tua agar lebih mengetahui cara memberikan pendidikan yang benar bagi anak pada masa usia dini.

Program ini akan dilaksanakan di beberapa wilayah yang mengalami kasus serupa, seperti Ngudi Ilmu (desa Ngglonggong kec. Balerejo), Rintisan (desa PP kec. Saradan), Pelangi II (desa Garon Kec. Balerejo), Berkah Ilmu dan Brumbun (Wungu). Pilihan tempat di atas didasari oleh kebutuhan akan pendidikan anak usia dini dan belum terjangkau oleh adanya PAUD intensif di wilayah-wilayah tersebut. Program ini juga akan sangat membantu orang tua agar lebih mengetahui cara memberikan pendidikan yang benar bagi anak pada masa usia dini.

\section{METODE PELAKSANAAN PROGRAM}

Materi kegiatan anak dikembangkan dengan merujuk pada "menu pembelajaran generik". Materi disampaikan melalui kegiatan bermain yang terencana, menarik, dan dapat memotivasi anak untuk mengembangkan sendiri seluruh potensi yang dimiliki. Program pembelajaran mengacu pada rancangan pelaksanaan pembelajaran harian, mingguan, dan tahunan dan disesuaikan juga dengan kebutuhan peserta didik, sehingga proses pembelajaranya lebih fleksibel dibanding dengan pendidikan formal. Dalam program pembelajarannya kader melihat dari aspek pengembangan peserta didik yaitu dari segi moral dan nilai agama, sosial emosional dan kemandirian, kemampuan bahasa, kognitif, serta fisik/motori (kasar dan halus).

\section{HASIL DAN PEMBAHASAN}

Pelaksanaan Pos PAUD dan Wahana Dolanan dilaksanakan selama dua bulan, tepatnya pada bulan Maret dan April 2014 tiap
Selasa-Jum'at jam 15.00-17.00 WIB. Materi kegiatan antara lain adalah Kegiatan Posyandu, Belajar sambil bermain, TPQ serta pemberian makanan dan minuman bergizi bagi anak.

Salah satu kegiatan yang dapat meningkatkan minat dan antusiasme anak adalah melalui wahana dolanan anak adalah dengan memberikan permainan-permainan yang dapat disajikan diselingi dengan pemberian pendidikan karakter anak seperti kerjasama, saling berbagi, dan lain-lain.

Permainan atau dolanan yang diperkenalkan anak tidak selalu dengan hal-hal yang bersifat modern. Namun permainan yang mudah dan asik sudah cukup untuk menghibur dan membangkitkan minat anak, seperti: bermain dengan sedotan dan karet, dengan tali, bermain nama-nama atau apapun yang dikuasai oleh pembimbing. Namun permainan yang diberikan harus sesuai dengan kebutuhan anak dan memiliki nilai-nilai kebajikan. Sehingga permainan yang diberikan tidak memberikan dampak negatif bagi anak tetapi dapat mendidik karakter anak.

Selain program-program diatas, penulis juga ikut melaksanakan program-program TPQ (Taman Pendidikan Alquran) bagi anak usia dini di Desa Suren. Hal ini dikarenakan keseluruhan anak usia Dini beragama Islam sehingga program TPQ dipilih untuk meningkatkan Iman dan pengenalan agama Islam bagi anak-anak tersebut. Materi pokok program TPQ yang diajarkan adalah pengenalan hafalan bacaan shalat, doa-doa sehari-hari, pengenalan huruh arab, serta kemampuan membaca Alquran yang dimulai dengan Iqro' jilid 1 sampai 6, juz ama dan Alquran.

Dalam mendidik / membina anak dalam program TPQ, metode pembinaan yang digunakan adalah secara klasikal dan juga secara perorangan (privat). Metode klasikal yaitu membimbing anak secara kelompok berdasarkan pembagian kelas. Metode ini dilakukan pada waktu kegiatan belajar mengajar khususnya dalam penyampaian materi-materi tambahan.

\section{KESIMPULAN}

Dari perspektif tersebut di atas dapat kami simpulkan sebagai berikut:

a) Penelitian Program Ipteks Bagi Masyarakat (IbM) ini merupakan manifestasi dari Tri Dharma Perguruan Tinggi yang harus kita kembangkan bersama serta merupakan cara yang tepat untuk menimba pengetahuan dan pengalaman tidak hanya mahasiswa sebagai 
bekal kehidupan kelak melainkan juga anggota masyarakat yang memiliki kepedulian kepada lingkungannya.

b) Pada pelatihan ini, para mahasiswa sebagai pelaksana antusias untuk melakukan perbaikan terhadap pengajaran dan bimbingan yang akan dan telah mereka lakukan, mengingat kendala-kendala seperti kurang lengkapnya wahana dolanan anak karena dana tidak menjadikan hambatan untuk terlaksananya program ini.

c) Latar belakang dari para mahasiswa yang berasal dari tingkat serta jenis pendidikan yang berbeda, bahkan bukan berlatar belakang ilmu pendidikan dapat sedikit diupayakan kesenjangannya dengan kegiatan belajar mengajar optimal yang diharapkan.

\section{REFERENSI}

Departemen Pendidikan Nasional. 2003. Kurikulum 2003 Standar Kompetensi TK dan RA. Jakarta.

Hasan, Maimunah. 2009. Pendidikan Anak Usia Dini. Jogjakarta: DIVA Press

Kartini Kartono, 1999. Psikhologi Anak. Bandung: Alumni

Piaget, Jean, Play, Dreams, and Imitation in Chilhood.(London: Hienemann, 1951)

Suyanto, Agus,at.al. 1982. Psikologi Perkembangan. Jakarta. Aksara Baru. 